\title{
p53 signaling in cancer progression and therapy
}

\author{
Hany E. Marei ${ }^{1 *} \mathbb{C}$, Asmaa Althani ${ }^{2}$, Nahla Afifi ${ }^{3}$, Anwarul Hasan ${ }^{4}$, Thomas Caceci ${ }^{5}$, Giacomo Pozzoli 6 , \\ Andrea Morrione ${ }^{7}$, Antonio Giordano ${ }^{7,8}$ and Carlo Cenciarelli ${ }^{9}$
}

\begin{abstract}
The p53 protein is a transcription factor known as the "guardian of the genome" because of its critical function in preserving genomic integrity. The TP53 gene is mutated in approximately half of all human malignancies, including those of the breast, colon, lung, liver, prostate, bladder, and skin. When DNA damage occurs, the TP53 gene on human chromosome 17 stops the cell cycle. If p53 protein is mutated, the cell cycle is unrestricted and the damaged DNA is replicated, resulting in uncontrolled cell proliferation and cancer tumours. Tumor-associated p53 mutations are usually associated with phenotypes distinct from those caused by the loss of the tumor-suppressing function exerted by wild-type p53protein. Many of these mutant p53 proteins have oncogenic characteristics, and therefore modulate the ability of cancer cells to proliferate, escape apoptosis, invade and metastasize. Because p53 deficiency is so common in human cancer, this protein is an excellent option for cancer treatment. In this review, we will discuss some of the molecular pathways by which mutant p53 proteins might perform their oncogenic activities, as well as prospective treatment methods based on restoring tumor suppressive p53 functions.
\end{abstract}

Keywords: p53 signaling, Tumor suppressor gene, Gain of function mutation, Cancer progression, Cancer therapy

\section{Introduction}

Tumor suppression is the main function of $\mathrm{p} 53$ protein, which is encoded by the TP53 gene on human chromosome 17 . The p53 protein is posited to inhibit the phenotypic and genomic alterations associated with cancer development through a complex interplay with several signaling pathways known to play critical roles in essential cellular processes such as cell division, maintenance of genomic stability, apoptosis, autophagy, immune response, and regulation of tumor microenvironment (TME) $[1,2]$.

Binding of wild-type p53 protein to specific DNA response elements induces the expression of a wide array of genes that ultimately guard against cancer

*Correspondence: hanymarei@mans.edu.eg

1 Department of Cytology and Histology, Faculty of Veterinary Medicine, Mansoura University, Mansoura 35116, Egypt

Full list of author information is available at the end of the article development and progression [3]. Under physiological conditions, exposure of cells to different stress signals activates the p53 signaling pathway, allowing the cells to activate several transcriptional programs including cell cycle arrest, DNA repair, senescence, and apoptosis leading to suppression of tumor growth [4].

In most if not all human malignancies, inactivation of the TP53 gene usually occurs through the acquisition of loss of function mutations or negative regulation of wildtype p53 proteins. Inactivation of the TP53 gene drives invasion, proliferation, and cell survival, thereby facilitating cancer progression and metastasis [5]. More than $75 \%$ of TP53 gene mutations result in loss of wild-type p53's activities. Mutated p53 proteins might act either as dominant negative over wild-type p53 action [6], or gain novel tumorigenic properties counteracting the protective function of wild-type p53 [7, 8].

Two homologs of the tumour suppressive transcription factor p53, p73 and p63, play crucial roles in cancer original author(s) and the source, provide a link to the Creative Commons licence, and indicate if changes were made. The images or other third party material in this article are included in the article's Creative Commons licence, unless indicated otherwise in a credit line to the material. If material is not included in the article's Creative Commons licence and your intended use is not permitted by statutory regulation or exceeds the permitted use, you will need to obtain permission directly from the copyright holder. To view a copy of this licence, visit http://creativecommons.org/licenses/by/4.0/. The Creative Commons Public Domain Dedication waiver (http://creativeco mmons.org/publicdomain/zero/1.0/) applies to the data made available in this article, unless otherwise stated in a credit line to the data. 
development. Because the p53 family members have a lot of structural similarities, p73 and p63 can bind to most p53-responsive promoters and initiate transcription. Apart from shared functions with p53 (e.g., activation of apoptosis in response to cellular stress), structural variability within the family has given p63 and p73 different responsibilities. The p53 family members p73 and p63 play overlapping and distinct roles in development and homeostasis. The functional linkages between family members can be better appreciated by looking at the expression of the p73 and p63 isoforms in human tissue. TP63 expression has been found to be significantly related across tissues. In tissues with concurrent mRNA expression, nuclear co-expression of both proteins was detected in the majority of cells [9].

Here we will highlight recent advances in the understanding the regulatory network by which mutant p 53 proteins might modulate molecular signaling pathways involved in cancer progression and/or protection.

\section{p53 and cancer progression}

Mutation in the TP53 gene is detectable in about $50 \%$ of human breast, colon, lung, liver, prostate, bladder, and skin cancer. Upon DNA damage, wildtype p53 acts in restraining the process of cell replication until the damage is repaired, thus preventing the propagation of DNAdefective cells and the acquisition of a cancer phenotype (Fig. 1). On the other end, TP53 mutations affect cell cycle and cells loose control of cell proliferation leading to propagation of damaged DNA into their progenies, which become transformed into cancerous cells.

The wild-type TP53 gene is translated into p53 proteins, which are transcription factors with an important role in orchestrating a variety of cellular responses such as DNA repair, cell cycle arrest, cellular senescence, cell death, cell differentiation, and metabolism thereby driving inhibitory molecular processes on cancer growth (Fig. 1) preserving genomic integrity, thus acting as "guardian of the genome" $[10,11]$.

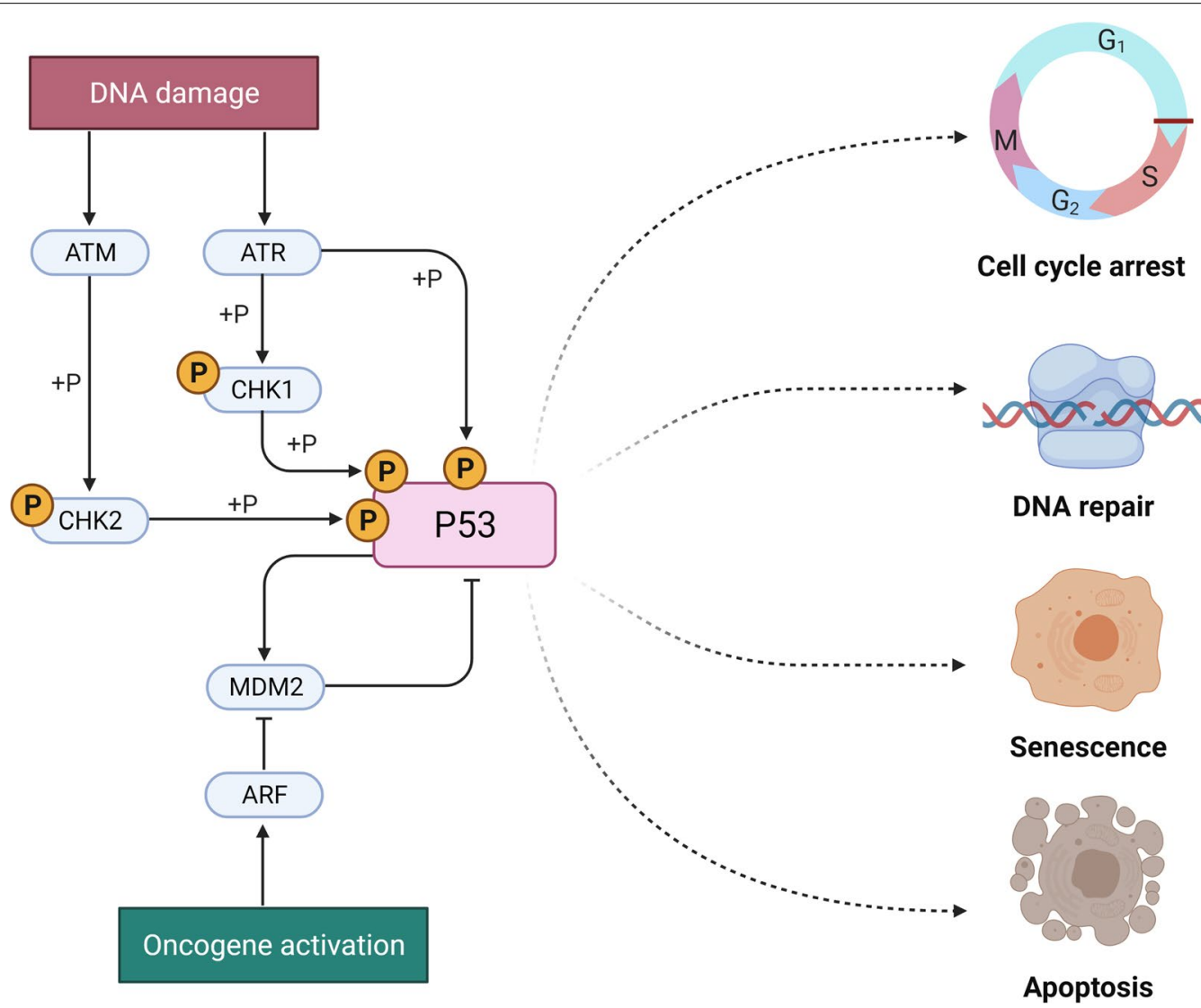

Fig. 1 ATM (ataxia telangiectasia mutated) and ataxia-telangiectasia-mutated-and-Rad3-related kinase (ATR) protein kinases phosphorylate p53 at serine 15 to activate and enhance the p53 stability. The phosphorylation of a variety of substrates, including casein kinase (CK1), checkpoint kinase 1 (Chk2), and p53, regulates cancer cell viability by modulating many critical biochemical pathways that lead to cell cycle arrest, DNA repair, senescence, and death 
Nuclear p53 phosphoprotein regulates normal cell proliferation, and accumulation of non-functional mutated p53 in tumor cell nuclei is associated with the development and/or progression of several neoplastic diseases, including breast cancer [12]. Activation of p53 induces senescence and cell-cycle arrest under excessive oncogenic stress and this is a crucial mechanism regulating the inhibition of tumorigenesis. Oncogenic cues often converge on key signaling nodes involved in the regulation of mTOR kinase [13]. Cell proliferation is induced by inactivating the $\mathrm{p} 53 / \mathrm{p} 21 \mathrm{Cdk}$-interacting protein 1 (Cip1) complex via Ras-dependent and-independent stimulation of the Raf/MEK/ERK cascade. These findings point to the importance Ras oncogenic activity and p53 inactivation in human cancer. [14]. The p53/p21/p27 and p53/Bcl-2/ Bax pathways affect many biological processes including cell proliferation, G2/M phase and apoptosis [15] as in fact 53 tumor suppressive function might work through the recruitment or regulation of other tumor suppressor proteins such as the Inter-Alpha-Trypsin Inhibitor Heavy Chain 5 proyein, encoded by the ITIH5 gene. p53 directly binds to the promoter of ITIH5 in melanoma cells, promoting ITIH5 transcription and therefore suppressing melanoma cell proliferation and migration, likely by downregulating KLF4 transcriptional activity [16]. ZEB1 and ZEB2 are transcription factors that induce epithelial-mesenchymal transition (EMT), while p53 inhibits EMT by suppressing ZEB1 and ZEB2 expression (Fig. 3) [17].

\section{Mechanism of action of mutant $\mathrm{p} 53$ Mutant $p 53$ and modulation of wild-type $p 53$ function}

In contrast to wild-type p53 anti-tumor protective activity, mutant p53 proteins have oncogenic action in culture cells [18], and promote metastasis and genomic instability in mice models $[19,20]$. Mutations of p53 are often alterations in the central DNA-binding domain and several hotspots such as R175, G245, R248, R249, R273 and R282, have been so far identified [21]. p53 mutations are subdivided into two main categories-structural and DNA-contact mutations, which affect either folding of the p53 protein or the transcriptional activity of p 53 and regulation of target genes, respectively. In both cases, the structural stability of p53 is altered and p53 might acquire a gain/loss-of-function phenotype [22, 23]. One of the major consequences of p53 mutant activities is altered gene expression, and in most cases, their ability to bind canonical p53 elements is severely hampered [24]. The interaction of mutant $\mathrm{p} 53$ proteins with non-canonical/different response elements might induce an oncogenic response as in fact mutant p53 proteins might act as a tumor-initiating transcriptional factors [25]. Mutant p53 proteins may also control gene expression through different mechanisms in which they interact directly with DNA sequences that bind to nuclear matrix regions, giving another way to change/regulate gene expression [26].

\section{Binding/interaction of mutant $p 53$ with key transcription factors including $p 63 / p 73$ axis}

The interaction with the nuclear factor Y (NF-Y) which occurs in response to minor DNA damage, and dysregulates cycle checkpoints [27-31]. Mutant p53 proteins can also interact with other transcription factors to induce inhibitory responses [32]. The mechanisms by which $\mathrm{p} 53$ mutants control the functions and downstream effector genes of p63 and p73 family members, is intriguing and represent one of the best understood process relevant to the p53-transcription factor function [33, 34]. The existence of several isoforms further complicates this process, and interestingly, mutant p53 interaction with various isoforms of p63 and p73 was shown to increase the expression of p63 downstream genes [31,35]. Other transcriptional factors such as TopBP1and PIN1 promote or enhance binding of mutant p53 to p63, respectively [36, 37].

Published data reported that mutant p53 increases the ability to develop spontaneous metastasis in mice by inhibiting p63 and p73 functions [38]. Loss of p63 and/ or p73 activities is linked to the development of spontaneous tumors and the capacity of cancer cells to invade $[36,39,40]$. Modulation of the invasive ability of cancer cells is controlled by multiple p63 target genes, which are affected by the interaction between mutant $\mathrm{p} 53$ and $\mathrm{p} 63$. The mutant $\mathrm{p} 53 / \mathrm{Smad}$ complex, for example, inhibits p63 and promote TGF-induced metastasis [36]. A Pin1/ mutant p53 axis evokes aggressiveness in breast cancer through the inhibition of p63-regulated expression of Dicer [34, 39], and p53 mutants can prevent DEPDC1 (DEP domain containing 1) gene inhibition mediated by p63 [34]. The interaction of mutant p53 and p63 modulates cell migration and invasion by promoting recycling and signaling of cell surface receptors such as the epithelial growth factor receptor (EGFR) and the hepatocyte growth factor receptor (HGFR) [41]. Recruitment of diacylglycerol kinase (DGK $\alpha)$ in the invadopodia of migrating cells has been reported to enhance the p53/p63/ RCP-dependent invasion mechanisms [42]. Furthermore, p73 has a similar role to p63, and it plays a decisive role in enhancing key cellular processes including cell aging and apoptosis [43].

\section{Mutant $p 53$ and other regulatory mechanisms}

Mutant p53 also targets other regulatory molecules including microRNAs such as miR-130b, miR-155 and miR-205. p53 binding to microRNAs has been associated with not only altering the stability of those molecules, but 
also influencing crucial molecular pathways involved in invasion and metastasis through the modulation of transcripts such as ZEB1 and ZNF652 [44, 45]. One notable consequence is the existence of mutant p53 in many cancer types is usually associated with gain of invasive and metastatic activity. For example in non-small lung cancer (NSLC), low p53 expression and high PGC1 expression were linked to a shorter survival time in NSCLC patients [46].

Mutant p53 additionally regulates certain signaling cascades such as the mevalonate pathway which regulate tissue remodeling [47]. However, how mutant p53 interacts with diverse partner molecules and how this connection is linked to distinct functional role as gain-of-function or loss-of-function is still not totally understood. Amongthe different domains constituting the molecular structure of mutant $\mathrm{p} 53$, the $\mathrm{N}$ - and $\mathrm{C}$ - termini regulate the interaction of mutant p53 with p63 and p73 as well as other molecules. Specifically, the DNA-binding domain and C-terminus of mutant p53 inhibit p63 function, and play crucial roles in regulating cell invasion and apoptosis [37, 48]. Moreover, the interaction of the $\mathrm{N}$-terminus domain of the mutant p53 is crucial for inducing the expression of target genes such GRO1 and CXCL1 and transcriptional factors such as sterol regulatory element binding proteins (SREBPs) and thus it has been reported to modulate the drug-induced apoptosis [26, 27].

\section{Binding/interaction of mutant $p 53$ with other protein molecules}

In addition to the interactions with multiple transcription factors, mutant $\mathrm{p} 53$ proteins bind and regulate the function of other non-transcription factor proteins. In this regard, mutant p53 disrupts DNA-repair mechanisms by interacting with the DNA nuclease MRE11 [49]. Moreover, the interaction of mutant p53 with other proteins involved in cell cycle regulation such as BTG2 modulates $\mathrm{H}$-Ras, thereby enhancing oncogenic transformation [50]. Other mutant p53 targets are involved in the regulation of genomic stability including the topoisomerase 1 (Top1), and the binding of mutant p53 to Top1 led to loss of negative regulation induced by the wild-type p53 and induced hyper-recombination and genomic instability [51].

\section{Posttranscriptional modifications of mutant $p 53$}

p53 protein has a rapid turnover due to ubiquitination mediated by the E3 ubiquitin ligase MDM2 and subsequent proteasomal degradation $[52,53]$.

p53 stability in response to genotoxic stress is regulated by a variety of post-translational modification (PTMs) [54], including phosphorylation, acetylation, methylation, glycosylation, ubiquitination, and sumoylation, which occur in different regions of the $\mathrm{p} 53$ protein, and play crucial role in regulating of p53 stability and localization, thereby affecting p53 ability to modulate cell proliferation and cell death [55].

Phosphorylation of $p 53$ and its role in cancer progression and apoptosis regulation Different serine $(\mathrm{S})$ and threonine $(\mathrm{T})$ phosphorylation sites have been identified on p53 proteins particularly in the $\mathrm{C}$ - and $\mathrm{N}$-terminal domains [56]. Notably, Ser 15 phosphorylation is pivotal in the activation of p53 [57] as in fact it enhances p53 stability by promoting its dissociation from the MDM2 ubiquitin ligase [58]. ATM (ataxia telangiectasia mutated) and ataxia-telangiectasia-mutated-and-Rad3-related kinase (ATR) protein kinases $[54,55]$ phosphorylate p53 at serine 15 and activate and improve the stability of p53 by enhancing the interaction between $\mathrm{p} 53$ and histone/lysine acetyltransferase (HATS) [59]. ATM- and ATR-mediated phosphorylation of downstream substrates, including casein kinase (CK1), checkpoint kinase 1 (Chk2), and p53, limits cancer cell viability by modulating many critical biochemical pathways leading to cell cycle arrest, DNA repair, senescence, and death. [60].

Phosphorylation of p53 on other serine residues activates/modulates $\mathrm{p} 53$ functions, and it associated with cell exposure to different toxic or damaging stimuli such as UV and IR (Fig. 2). DNA damage after UV and IR exposure mediates stabilization of human p53 through phosphorylation on Ser-20 [61]. Apoptosis is triggered instead by $\mathrm{p} 53$ phosphorylation on Ser46, which is mediated by many kinases including homeodomain-interacting protein kinase 2 (HIPK2), p38, and dual specificity tyrosine-phosphorylation regulated kinase 2 (DYRK2) [62, 63]. Genotoxic stress causes transactivation of p53 by modulating p53 phosphorylation on its amino terminus, which regulates the interactions between p53 and MDM2 orp300/CBP $[64,65]$. The interactions of p53 with the apoptosis stimulating proteins of p53 (ASPP) proteins, as well as p300, control its apoptotic activity [66, 67].

Acetylation of p53 and its effects on p53 transactivation and stability Acetylation of p53 is another post-translational reversible enzymatic process by which p53 action is fine-tuned in response to different cellular toxic signals including genotoxic stress and damage of DNA [68] and many studies have looked at the role that acetylation plays in regulating p53 action as a tumor suppressor (Fig. 2) [68].

p53 proteins is are acetylated on at defined amino acid positions. Particularly, lysines $(\mathrm{K})$ residues within the C-terminal regulatory domain (K370, K372, K373, $\mathrm{K} 381, \mathrm{~K} 382$, and $\mathrm{K} 386$ ) of $\mathrm{p} 53$ are key acetylation sites and play a crucial role in regulating p53 function [69, 70]. Acetylation of the aforementioned lysine residues 


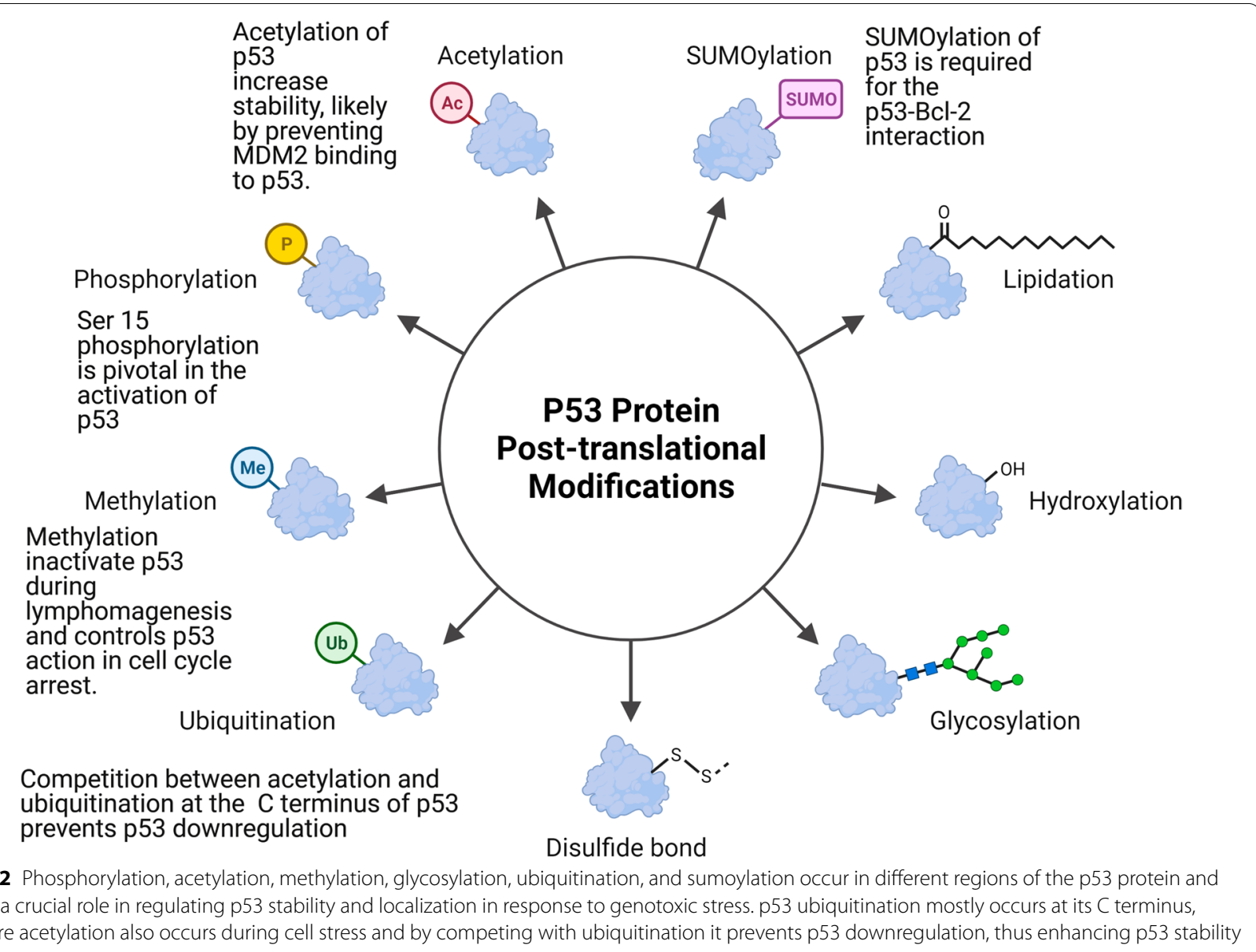

modulate p53 transcriptional activity and increase stability, likely by preventing MDM2 binding to 53 [56].

The transcriptional coactivator proteins $\mathrm{CBP} / \mathrm{p} 300$ control p53 activity in multiple ways., interaction between p300 and either p53 or E2F1 has a significant influence on early cell cycle progression, suggesting that p300 is involved in E2F and p53-regulated growth arrest pathways [71]. CBP/p300 proteins also contributes to MDM2-mediated ubiquitination of $\mathrm{p} 53$, which reduces p53 levels in the presence of genotoxic stress [72]. On the other hand, they also prevent p53 degradation by acetylating the protein's carboxyl terminus, which includes ubiquitination sites. Notably, K120 and K164 acetylation sites are located in the p53 DNA-binding domain, which is the most commonly mutated region of p53 in solid tumors, A K120 mutation was identified in Ewing's Sarcoma and esophageal SCC cells, whereas a K164 mutation was discovered in glioblastoma and bladder cancer cells [70] suggesting that acetylation of these particular residues is critical for $\mathrm{p} 53$ function.
The tumor suppressor action of p53 is modulated by methylation $\mathrm{P} 53$ lysine $(\mathrm{K})$ and arginine (R) residues can be methylated, and a growing number of studies have shown that p53 methylation occurs during the DNA damage response [73]. The effects of lysine and arginine methylation on chromatin structure and gene expression have been well characterized [74-76] In the tetramerization domain, PRMT5 methylates p53 at different arginine residues (R333, R335, and R337) [77], and this modifications likely inactivate p53 during lymphomagenesis and controls p53 action in cell cycle arrest (Fig. 2) [78]. SET and MYND domain-containing protein 2 (SMYD2) monomethylate p53 at K370 and decrease $\mathrm{p} 53$-mediated transactivation. In addition, this methylation event reduces p53 binding to the promoters of its target genes, such as p21 [79]. SET7/9-evoked monomethylation of K372 enhances p53-mediated activation of downstream targets, whereas SET8-mediated monomethylation of $\mathrm{K} 370$ reduces p53 transcriptional activity [80]. 
SUMOylation of 553 controls its localization The tumor suppressor p53 has dynamic nuclear output because its tetramer domain contains a leucine-rich nuclear export signal (NES) region [81]. Another NES is recognizable in the N-terminal transactivation domain of p53 and its phosphorylation blocks p53 nuclear output, leading to p53 nuclear accumulation [82]. SUMO-1, SUMO-2 and SUMO-3 promote sumoylation of p53 at K386, which accelerates p53 nucleocytoplasmic shuttling (Fig. 2) [83].

P53 promotes the synthesis of pro-apoptotic genes in the nucleus by increasing p21 expression, [84]. The majority of the anti-apoptotic activities of p53 occurs in the nucleus, particularly while the cell is at rest.

Topors and other members of the PIAS family SUMOylate the p53 protein at a single location, K386, on the protein. [85]. When PAISy was administered to p53, K386 sumoylation and K120 acetylation of p53 occurred, and Tip60 was activated as a result. Despite the fact that these two changes are not mutually exclusive, they act as "binary death signals," causing p53 cytoplasm accumulation and PUMA-mediated autophagy. [86].

The growth suppressive action of p53 is lost when it is shuttled into the nucleus, where it may instead promote cellular proliferation. Cytosolic p53 has a nontranscriptional function and. Can interact with $\mathrm{Bcl}$ (B cell lymphoma/leukemia)-2, thereby counteracting its anti-apoptotic impact [87]. Furthermore, SUMOylation of $\mathrm{p} 53$ is required for the $\mathrm{p} 53-\mathrm{Bcl}-2$ interaction [88] and high levels of cytoplasmic p53 localization is associated with poor prognosis and hormone-resistant disease [89].

Ubiquitination and ubiquitin-like proteins that impact on the p53 pathway Ubiquitination plays an important role in regulating protein function as in fact it modulates proteins trafficking, localization, stability and activity. It also has an important role in regulating protein-to-protein interactions [90]. The role of ubiquitination in regulating transcriptional factor function has lately received a lot of attention. p53 ubiquitination mostly occurs at its C terminus, where acetylation also occurs during cell stress and by competing with ubiquitination it prevents p53 downregulation, thus enhancing p53 stability (Fig. 2) [91]. However, the impact of ubiquitination on the function of the P53 tumor suppressor is very broad and beyond the scope of this article. Recent review papers, such as those by Chen et al., nicely cover this topic [92].

\section{Mutant p53 and other cancer related signaling pathways 0.1 Mutant $p 53$ and STAT signaling pathway}

Through a mechanism involving Stat3, which binds to the p53 promoter in vitro and in vivo, oncogenic signaling pathways decrease the rate of p53 gene transcription. STAT3-induced inhibition is partially abrogated by a site-specific mutation of a STAT3 DNA-binding site in the p53 promoter. STAT3-induced inhibition is partially abrogated by a site-specific mutation of a STAT3 DNA-binding site in the p53 promoter. STAT3 activity also has an impact on the p53 response genes and UVinduced cell growth arrest in normal cells. Furthermore, inhibiting STAT3 in cancer cells increases p53 expression, resulting in tumour cell death mediated by p53 [9395]. STAT3, like STAT5 and STAT6, affects the tumor microenvironment (TME), boosting immunosuppressive TMEs and decreasing anti-tumor immunity [96].

STAT proteins have an important role in regulating p53 activation. STAT3 reduces the tumor-suppressive action of p53 by inhibiting its expression [97]. As shown in breast [98] and prostate cancer cells [99], wild-type p53 affects tyrosine phosphorylation and hence limits STAT3 DNA-binding activity in a manner that resembles a feedback loop.

This reciprocal regulation between activated STAT3 forms and p53 does not occur when p53 is mutated (Fig. 3). The ability of phosphorylated or alternatively spliced STAT3 proteins to increase mutant p53 expression might pose a risk for cancer. Notably, constitutive STAT3 activation is only detectable in cancer cells expressing inactivating mutations or deletions of p53, allowing cancer cells to evade inhibition by the wild-type p53 pathway, particularly after DNA damage. The presence of STAT3 and p53 in cancer cell lines from prostate (DU145 and TSU), breast (MDA-MB-468 and SK-BR-3) and ovarian (MDAH 2774, SKOV-3, and CAOV-3) cancer confirms this theory (which [99]. These cell lines express constitutively active STAT3 proteins in conjunction with mutant p53 or p53 null background. According to a recent study, the R248Q p53 mutation is associated with hyperactive STAT3/JAK signaling, and therapeutic ablation of this gain-of-function mutant p53 in colorectal cancer inhibits STAT3-mediated tumor growth and invasion [100].

In colorectal cancer (CRC), the frequent hotspot mutations mutp53R248Q and mutp53R248W exhibit gain-offunction activities and constitutively bind to and activate STAT3 thereby enhancing proliferation and invasion in CRC mouse model. In mutp53R248W-expressing PDAC cells, genetic or pharmacological STAT3 depletion phenocopied mutp53 depletion and decreased cell viability and migration indicating that the mutp53R248W signals through the STAT3 transforming axis [101]. Modulation of STAT3-dependent gene expression altered biological responses, including cell cycle progression and p53 response [102].

Mutant p53 and NF-kappaB (NF-kB) signaling pathway The NF- $\mathrm{KB}$ and p53 pathways are often seen as antagonistic transcriptional networks. While wild-type 


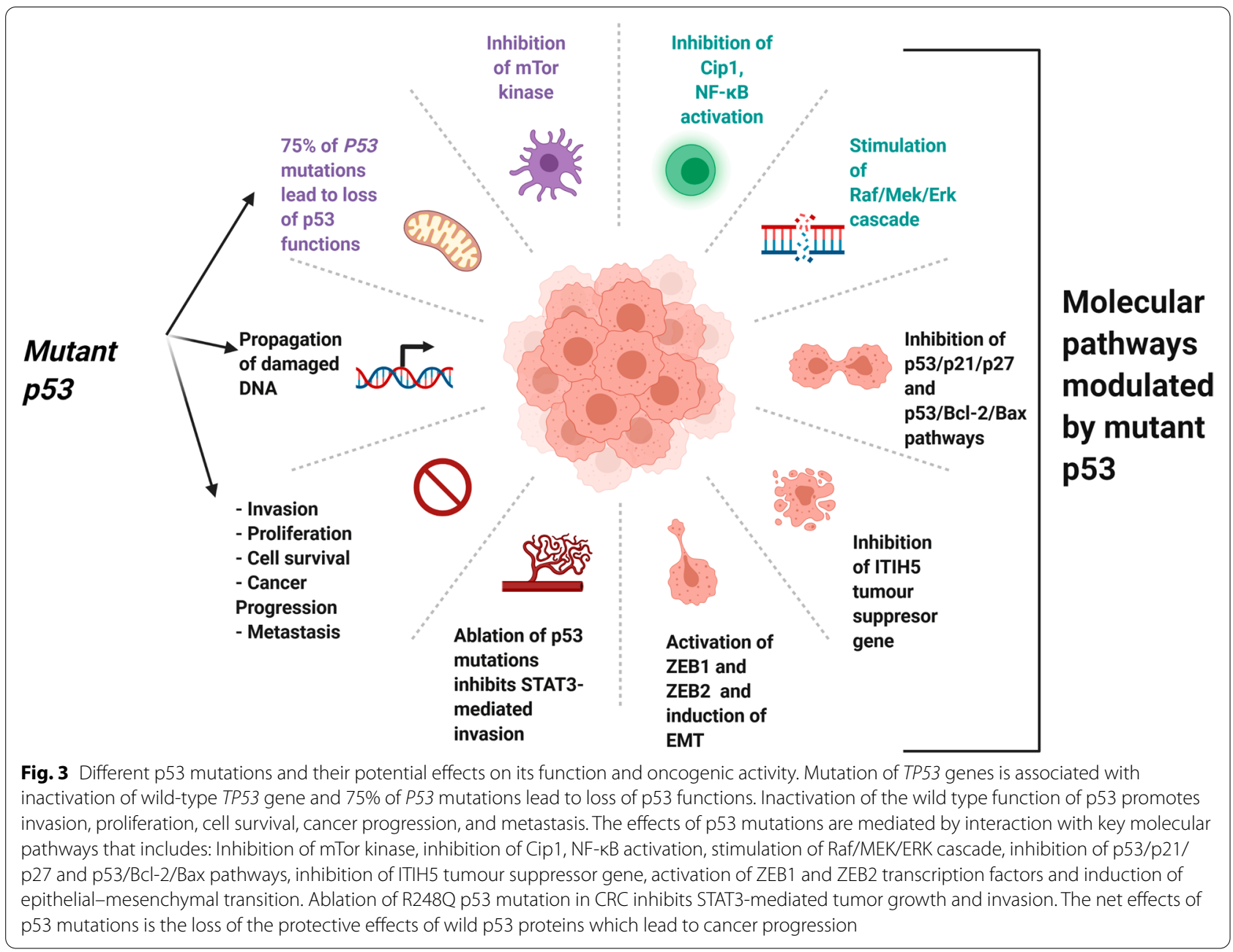

p53 traditional function is growth restriction, NF-kB's promotes cell survival and inflammation [103]. However, these two pathways can cross-talk and cooperate in determining similar biological responses [104]. NF-kB cooperates with wild-type p53 in mediating apoptosis of IMR-90 cells but not of human BJ fibroblasts [105] and functionally interact with wild-type p53 in promoting senescence [106]. In addition, in macrophages and monocytes NF- $\mathrm{kB}$ is necessary for $\mathrm{p} 53$-dependent regulation of many proinflammatory genes in order to enhance tissue and inflammatory responses to damaging signals [107].

In mutant p53 animal models, Cooks et al. discovered that mutant $\mathrm{p} 53$, in combination with tumor necrosis factor (TNF), prolongs NF- $\mathrm{BB}$ activation, resulting in a chronic inflammatory phenotype and colon cancer growth. These data support a connection between accumulating missense p53 mutations and NF- $\mathrm{kB}$ activation in human cancers linked with colitis [108].

The combined binding of $\mathrm{NF}-\mathrm{kB}$, the $\mathrm{R} 273 \mathrm{H} \mathrm{p} 53$ mutant, and other mutant versions of p53 to these enhancers regulates RNA polymerase II recruitment to these elements in colorectal carcinomas, boosting mRNA synthesis and activation of tumor-promoting genes. Mutant p53, in combination with NF-kB, can therefore alter the inflammatory tumor microenvironment (TME), inducing in both epithelial and and nonepithelial cells the expression of cancer-promoting gene (Fig. 3) [107]. Using 9-aminoacridine derivatives in renal cell carcinomas and small molecule curaxins in several cancer cell lines and mouse tumour xenografts to restore wild-typep53 function is a rational approach that has previously been demonstrated [109, 110]. In mutant p53 background, approaches aiming at restoring wild-type p53 expression might potentially improve existing NF-kB-dependent therapies [111].

\section{Mutant p53 and tumor microenvironment (TME)}

CAFs (cancer-associated fibroblasts) are an essential part of the TME and modulate inflammatory and leukocyte recruitment signals [112]. When CAFs come into contact 
with cancer cells, they trigger the IFN- $\beta$ pathway, which interacts with wild-type p53 in fibroblasts to inhibit cancer cell migration and decrease tumor development (Fig. 4) [113, 114]. In contrast to its wild-type counterpart, mutant p53 in cancer cells regulates and inhibits the tumor-suppressive response to IFN- $\beta$ via inhibiting STAT1 phosphorylation and downstream targets of IFN$\beta$. IFN- $\beta$ produced by CAFs, in turn, can lower the amounts of mutant p53 RNA in tumors [115] The inflammatory microenvironment can disrupt the equilibrium of this regulatory network, causing a molecular stop that both suppresses and enhances the tumorigenic effects of mutant p53 in cancer cells [116]. Reactivating wild-type p53 activity might be a synergistic opportunity for targeting IFN-related therapy, as the mutational state of p53 is important for targeting IFN-related therapy.

Previous research has shown that the ECM can regulate p53 activity in cultured cells by sending pro-survival signals that reduce p53-evoked apoptotic effects [117]. In recent years, the reciprocal involvement of p53 in ECM regulation has been filled out, particularly in hypoxic situations [118]. The accumulation of reactive oxygen species (ROS) and inflammation are linked to hypoxic tumor environment. In hypoxic settings, hypoxia-inducible factors (HIFs) can enhance the production of pro-angiogenic factors such as vascular endothelial growth factor (VEGF) and platelet-derived growth factor (PDGF) [119]. R273H and R246I p53 mutations cooperate with HIF-1 to regulate transcription of ECM components in non-small cell lung cancer cells, favoring aggressive invasion and poor clinical prognosis [120].

\section{Mutant $p 53$ and cancer immunology}

Despite the fact that p53 mutations are uncommon in immune cells, p53 can impair cell-mediated immunity by creating specific molecular fingerprints in tumor or stromal cells that affect immune cell recruitment and activation [121]. It can also regulate the expression of the class 1 major histocompatibility complex (MHC-1) and the resulting immunological responses

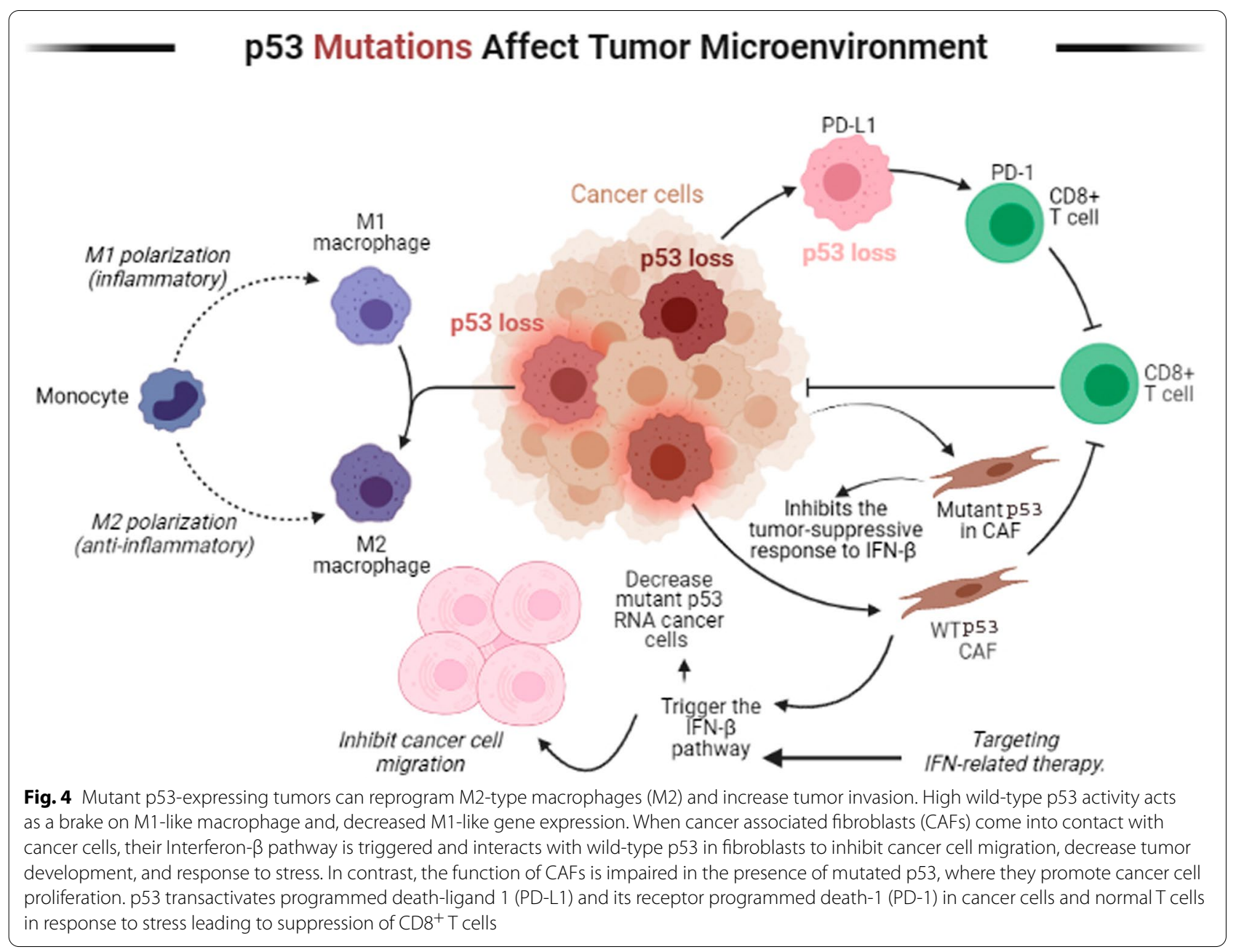


[122]. Myeloid-derived suppressor cells are a heterogeneous group of immune cells from the myeloid lineage. MDSCs strongly expand in pathological conditions such as chronic infections and cancer, as a result of an altered hematopoiesis [123]. Lymphocytic penetration, particularly cytotoxic $\mathrm{T}$ cells, is hindered when the wild-type p53 pathways are disturbed in ER-negative breast cancer and basal-like breast tumors. Both loss of heterozygosity and p53 mutations are linked to lower incidence of T cell infiltration and a worse prognosis [124]. Multiple genetically altered mouse breast cancer models with p53 loss increased inflammatory Wnt signaling in tumor-associated macrophages, resulting in systemic neutrophilia and finally metastasis [125].

Recent data have indicated that Immunological checkpoints and wild-type p53 are linked. p53 transactivates programmed death-ligand 1 (PD-L1) and its receptor programmed death-1 (PD-1) in cancer cells and normal $\mathrm{T}$ cells in response to stress (Fig. 4) [126]. The connection between PD-L1 on tissue and PD-1 on T cells decreases activation signals produced by $\mathrm{T}$ cells after antigen recognition, and this immune checkpoint controls inflammation. Tumor amplification of PD-L1, on the other hand, takes advantage of this immune checkpoint mechanism to reduce tumor surveillance and build immunological tolerance [127]. As a result, in some context, mutant p53 might be a useful biomarker for immunotherapy response and might associate with a better prognosis due to distinct immunogenic signals [128].

Wild-type p53 controls Toll-like receptor (TLR) gene expression in T-lymphocytes and to a lesser extent in macrophages in a way that is dependent on genetic stress and the host genetic background [129]. Polymorphisms in the $\mathrm{p} 53$ response areas of TLR gene promoters, in particular, confer different levels of susceptibility to genetic stress and infection Different levels of vulnerability to genetic stress and infection are conferred by polymorphisms in the $\mathrm{p} 53$ response regions of TLR gene promoters, in particular. [130]. The anti-tumor effects of TLR induction become obvious when considering the importance of APC reactivation in the cancer microenvironment, where activated TLR pathways increase immune recognition and action against tumor-antigen carrying cells. On the other hand, TLR expression in tumor cells and surrounding cells is pro-tumorigenic [131]. TLR4 is expressed in several human cancer cell lines, including MDA-MB-231, MCF7, A549, and H1291. In response to LPS treatment, TLR4 activates the p38 MAPK and NF-kB signaling pathways in A549 and H1299 cells. This activation increases cancer immune evasion and resistance to apoptosis by secreting immunosuppressive cytokines such as VEGF, TGF-, and IL-8 [132].
MAPK and NF-kB activation are common threads in TLR-4-expressing colorectal tumors, and it is associated with increasing proliferative capacity, apoptotic resistance, and metastatic potential [133]. In breast cancer, TLR-4 expression has been associated with poor survival and invasiveness [134]. Humans and apes are the only species that have a p53-TLR regulatory axis [135]. This evolutionary gap is significant for considering TLR-mediated cancer treatment since mouse models do not mimic the regulatory axis that is present in humans [136]. p53 mutations not only alter TLR gene expression, but also have a number of additional consequences. TLR3 sensitivity and reactivity to known ligands are affected by these alterations, which modulate type I interferon response and downstream genotoxic-stressinduced apoptosis. This control of TLR3 responsiveness is directly linked to the expression of transcriptionally active or TLR3-enhancing p53 mutants like $\mathrm{P} 151 \mathrm{H}$ and $\mathrm{R} 337 \mathrm{H}$, while other mutations might instead inhibit the TLR3-mediated immune response [137].

Macrophages are one of the most prevalent immune cell types in the TME [138]. According to most research, both M1-like and M2-like polarization are often linked to increased levels of p53 expression. High levels of p53 activity function as a brake on M1-like macrophage polarization, avoiding detrimental long-term activation of the inflammatory NF- $\mathrm{B}$ and STAT1 pathways and, as a result, decreased $\mathrm{M} 1$-like gene expression over time (Fig. 4) [139]. Exosomal-mediated microRNA transfer is crucial in many cancers, and another mutant-specific GOF of p53 might be relevant as well [140]. Exosomes from $\mathrm{R} 248 \mathrm{~W}$ and $\mathrm{R} 273 \mathrm{H}$ mutant p53-expressing colon cancer cells had a high concentration of miR-1246, a microRNA related to invasiveness and stemness [141]. Mutant p53-expressing tumors can cause comparable non-cell-intrinsic reprogramming of macrophages into TAM-like M2 phenotypes via exosomal microRNA transfer (Fig. 4). These reprogrammed macrophages additionally presented enhanced degradation of the extra cellular matrix and became more invasive when compared with macrophages that were introduced to tumor cells that did not carry any p53 mutation [142].

\section{P53 and cellular senescence}

In the elderly, cellular senescence and the accompanying secretory phenotype (SASP) induce illness. Targeting senescent cells through SASP regulation, or cellular reprogramming could be a new therapeutic path for cancer and age-related illnesses like neurodegeneration, pulmonary fibrosis, and renal failure. The TP53 gene, encodes 12 or more p53 protein isoforms, regulates cellular senescence. The various p53 isoforms are generated 
by the use of different transcriptional and translational start sites, as well as alternative mRNA splicing. These shortened p53 isoform proteins play significant roles in cellular senescence, apoptosis, and DNA repair, as well as modulation of full-length p53-mediated cellular senescence, apoptosis, and DNA repair [143].

ELK1 could be targeting the promoters of TP53 and RB2/P130 [144]. This finding is intriguing because P53 and $R B 2 / P 130$ were identified as the major regulators of senescence in human MSCs [144-146].

In the context of senescence, p53 plays a critical role in deciding the fate of cells, and its activation can be DDRdependent or DDR-independent [147]. In the first example, replicative stress activates the DNA damage repair cascade by causing telomere erosion, DNA damage, hyperactivation of oncogenes, and inactivation of oncosuppressors (oncogene induced senescence, OIS) [148]. By phosphorylating both p53 and its ubiquitin ligase Mdm2, ATM/ATR activates the p53/p21cip1 axis, resulting in the stability of p53 levels [149].

The role of DDR activation as a necessary and causal element in p53 activation and senescence induction has lately been questioned. Many recent investigations have shown that many OIS routes can really activate p53 without going through the DDR as in fact they might occur throughAKT via downregulation of MnSOD, through the onco-suppressor PTEN depletion, prompting mTORC1 and mTORC2 to bind to p53 instead of MDM2, and MAPK p38 by direct phosphorylation of p53 [149]. These findings, as well as the mechanisms they describe, highlight the critical role of p53 and p53-triggered senescence in the inhibition of carcinogenesis following the occurrence of a first mutation [150].

\section{Potential of p53 signaling targeting for cancer therapy}

Because wild-type p53 is an efficient promoter of apoptosis and senescence [145] in tumor cells, reactivating wildtype characteristics of p53 mutants, which are commonly overexpressed in cancer, is a viable therapeutic strategy.

Several studies have shown that transfection of cancer cells with wild-type p53 expressing plasmids can induce apoptosis and/or growth arrest, implying that a gene therapy method for cancer treatment could be based on restoring normal p53 expression and function. Several clinical research investigations using viral and non-viral vectors delivering p53 genes, alone or combined with other therapeutic agents, have been completed to far [151].

Some tumor-derived mutations that cause wild-type p53 loss-of-function can be restored by other point mutations that help stabilize the p53 protein, indicating that the structural change is reversible [152]. PhiKan083 and PK7088 are small chemicals that bind p53 and generate the Y220C mutant, stabilizing it and boosting the amount of wild-type p53 [153]. Other molecules, including PRIMA-1, PRIMAmet/APR-246, CP-31398, and $\mathrm{SCH} 29074$, bind to mutant p53 proteins and interact with DNA binding domains to facilitate proper mutant protein folding and p53 function recovery. The 367-369 Zinc binding domain is required for the proper folding of wild-type p53, whereas zinc binding is absent in the R175H p53 mutant $[154,155]$.

When zinc is added to the structural mutants G245C and G245D, the wild-type structure is for the most part restored [156] As a consequence, the discovery of the ability of zinc to restore wild-type folding suggest that this technique might be able to restore anticancer drug chemosensitivity in cells harboring mutant p53 proteins [157]. NSC31926, a thiourea metal chelator, is able to restore wild-type p53 function in p53 mutant cell lines, most likely via boosting zinc bioavailability to p53 mutants [158]. Although certain components are designed to selectively inhibit mutant p53, many of them can also interact with and inhibit other members of the p53 family, including p63 and p73. A small compound called RETRA, which was identified in a screening of a drug used to identify stable wt p53, disrupts the interaction between mutant p73 and p53. RETRA increased the release of $\mathrm{p} 53$, which inhibited tumor cell survival and xenograft tumor development by activating the p73 gene.

Compounds like APR-246, PK11007, and COTI-2 are promising treatments for patients with trible negative (TN) breast tumours because p53 is mutated in the great majority of them. However,mutant p53 can work as a biomarker in breast cancer, is not clearly defined [159].

Critical Outcome Techonologies Inc.'s (COTI-2) thirdgeneration thiosemicarbazone, as well as particular peptides, have recently been shown to convert reactive mutant p53 protein to a form with wild-type characteristics. These drugs have been demonstrated to have anticancer action in preclinical models expressing mutant p53, which is consistent with the reactivation of mutant p53. Two of these drugs, APR-246 and COTI-2, have made it to clinical trials so far. APR-246 had no major side effects in a phase I/IIa clinical trial. APR-246 is now being tested in patients with advanced serous ovarian cancer in a phase Ib/II trial, while COTI-2 is being tested in patients with advanced gynaecological tumours in a phase I trial. However, whether any mutant $\mathrm{p} 53$ reactivating chemical is effective in the therapy of human cancer remains to be seen [160].

Shenzhen SiBiono GeneTech Co. Ltd. produced Gendicine (recombinant human p53 adenovirus), which was approved by the China Food and Drug Administration (CFDA) in 2003 as a first-in-class gene therapy treatment to treat head and neck cancer and went on 
the market in 2004. Gendicine is a biological therapy that can be administered via intratumoral injection, intracavity infusion, or intravascular infusion. Depending on the cellular stress circumstances, the wild-type (wt) p53 protein expressed by Gendicine-transduced cells is a tumour suppressor that is triggered by cellular stress and promotes cell-cycle arrest and DNA repair, or produces apoptosis, senescence, and/or autophagy. Based on more than 30 published clinical trials and 12 years of commercial use in over 30,000 patients, Gendicine has a proven track record of safety, and when combined with chemotherapy and radiotherapy, it has shown to produce much higher response rates than traditional therapies alone. In addition to head and neck cancer, Gendicine has been used to successfully treat a variety of other cancer kinds and stages. Thirteen published trials with long-term survival data found that Gendicine combination regimens result in considerably longer progression-free survival periods than standard treatments alone. Despite the fact that the p53 gene is mutated in more than half of all human malignancies, the presence of a p53 mutation had no effect on efficacy or long-term survival in Ad-p53-treated patients [161].

\section{Conclusions}

The growing understanding of mutant p53 actions has contributed to the identification of a number of compounds with promising therapeutic potential. However, further experiments are required to fully characterize mutant p53 function in cancer. The fact that mutant p53 might play a role in promoting metastasis - the primary cause of cancer-related mortality - is particularly attractive in terms of possible therapeutic applications. Although many tumors express mutant p53, it is unclear if the many mutations present on this protein have similar activity, and we might have to personalize therapy depending on the presence of a particular mutation rather than only consider whether a cancer express a wild-type vs a mutant p53 mutant.

\section{Authors' contributions}

Conceive the idea: HEM, CC, GP, AM. First draft: HEM, AA, NA, AH, AG. Edited the final draft: All authors. All authors read and approved the final manuscript.

\section{Funding}

Not applicable.

\section{Availability of data and materials}

All data are included in the manuscript

\section{Declarations}

Ethics approval and consent to participate Not applicable.
Consent for publication

Not applicable.

\section{Competing interests}

The authors declare that there is no conflict of interest regarding the publication of this article.

\section{Author details}

'Department of Cytology and Histology, Faculty of Veterinary Medicine, Mansoura University, Mansoura 35116, Egypt. ${ }^{2}$ Biomedical Research Center, Qatar University, Doha, Qatar. ${ }^{3}$ Qatar Biobank, Doha, Qatar. ${ }^{4}$ Department of Mechanical and Industrial Engineering, College of Engineering, Qatar University, Doha, Qatar. ${ }^{5}$ Biomedical Sciences, Virginia Maryland College of Veterinary Medicine, Blacksburg, VA, USA. ${ }^{6}$ Pharmacology Unit, Fondazione Policlinico A. Gemelli, IRCCS, Rome, Italy. ${ }^{7}$ Sbarro Institute for Cancer Research and Molecular Medicine. Center for Biotechnology, College of Science and Technology, Temple University, Philadelphia, PA, USA. ${ }^{8}$ Department of Medical Biotechnology, University of Siena, Siena, Italy. ${ }^{9}$ Institute of Translational Pharmacology-CNR, Rome, Italy.

Received: 16 October 2021 Accepted: 6 December 2021

Published online: 24 December 2021

\section{References}

1. Hafner A, Bulyk ML, Jambhekar A, Lahav G. The multiple mechanisms that regulate p53 activity and cell fate. Nat Rev Mol Cell Biol. 2019;20(4):199-210.

2. Timofeev $\mathrm{O}$. Mutant $\mathrm{p} 53 \mathrm{in}$ cancer progression and personalized therapeutic treatments. Front Oncol. 2021. https://doi.org/10.3389/fonc. 2021.740578.

3. Levine AJ. The many faces of p53: something for everyone. J Mol Cell Biol. 2019;11(7):524-30.

4. Vousden $\mathrm{KH}$, Prives $\mathrm{C}$. Blinded by the light: the growing complexity of p53. Cell. 2009;137(3):413-31.

5. Muller PA, Vousden KH. p53 mutations in cancer. Nat Cell Biol. 2013;15(1):2-8

6. Petitjean A, Mathe E, Kato S, Ishioka C, Tavtigian SV, Hainaut P, et al. Impact of mutant p53 functional properties on TP53 mutation patterns and tumor phenotype: lessons from recent developments in the IARC TP53 database. Hum Mutat. 2007;28(6):622-9.

7. Brosh R, Rotter V. When mutants gain new powers: news from the mutant p53 field. Nat Rev Cancer. 2009;9(10):701-13.

8. Oren M, Rotter V. Mutant p53 gain-of-function in cancer. Cold Spring Harb Perspect Biol. 2010;2(2):a001107.

9. Dötsch V, Bernassola F, Coutandin D, Candi E, Melino G. p63 and p73, the ancestors of p53. Cold Spring Harb Perspect Biol. 2010;2(9):a004887.

10. George P. p53 how crucial is its role in cancer. Int J Curr Pharm Res. 2011:3(2):19-25.

11. Suh Y-A, Post SM, Elizondo-Fraire AC, Maccio DR, Jackson JG, El-Naggar AK, et al. Multiple stress signals activate mutant p53 in vivo. Can Res. 2011;71(23):7168-75.

12. Allred DC, Clark GM, Elledge R, Fuqua SA, Brown RW, Chamness GC, et al. Association of p53 protein expression with tumor cell proliferation rate and clinical outcome in node-negative breast cancer. JNCI. 1993;85(3):200-6.

13. Loayza-Puch F, Drost J, Rooijers K, Lopes R, Elkon R, Agami R. p53 induces transcriptional and translational programs to suppress cell proliferation and growth. Genome Biol. 2013;14(4):1-12.

14. Drosten M, Sum EY, Lechuga CG, Simón-Carrasco L, Jacob HK, GarcíaMedina R, et al. Loss of p53 induces cell proliferation via Ras-independent activation of the Raf/Mek/Erk signaling pathway. Proc Natl Acad Sci. 2014;111(42):15155-60.

15. Qiu L, Liu H, Wang S, Dai X-H, Shang J-W, Lian X-L, et al. FKBP11 promotes cell proliferation and tumorigenesis via p53-related pathways in oral squamous cell carcinoma. Biochem Biophys Res Commun. 2021;559:183-90.

16. Liu J, Cao F, Li X, Zhang L, Liu Z, Li X, et al. ITIH5, a p53-responsive gene, inhibits the growth and metastasis of melanoma cells by downregulating the transcriptional activity of KLF4. Cell Death Dis. 2021;12(5):1-15. 
17. Kim T, Veronese A, Pichiorri F, Lee TJ, Jeon Y-J, Volinia S, et al. p53 regulates epithelial-mesenchymal transition through microRNAs targeting ZEB1 and ZEB2. J Exp Med. 2011;208(5):875-83.

18. Dittmer D, Pati S, Zambetti G, Chu S, Teresky AK, Moore M, et al. Gain of function mutations in p53. Nat Genet. 1993;4(1):42-6.

19. Lang GA, Iwakuma T, Suh Y-A, Liu G, Rao VA, Parant JM, et al. Gain of function of a p53 hot spot mutation in a mouse model of Li-Fraumeni syndrome. Cell. 2004;119(6):861-72.

20. Olive KP, Tuveson DA, Ruhe ZC, Yin B, Willis NA, Bronson RT, et al. Mutant p53 gain of function in two mouse models of Li-Fraumeni syndrome. Cell. 2004;119(6):847-60.

21. Duffy MJ, Synnott NC, O'Grady S, Crown J. Targeting p53 for the treatment of cancer. Semin Cancer Biol. 2020. https://doi.org/10.1016/j. semcancer.2020.07.005.

22. Sigal A, Rotter $V$. Oncogenic mutations of the p53 tumor suppressor: the demons of the guardian of the genome. Can Res. 2000;60(24):6788-93.

23. Cho Y, Gorina S, Jeffrey PD, Pavletich NP. Crystal structure of a p53 tumor suppressor-DNA complex: understanding tumorigenic mutations. Science. 1994:265(5170):346-55.

24. Ludwig RL, Bates S, Vousden KH. Differential activation of target cellular promoters by p53 mutants with impaired apoptotic function. Mol Cell Biol. 1996;16(9):4952-60.

25. Weisz L, Oren M, Rotter V. Transcription regulation by mutant $\mathrm{p} 53$. Oncogene. 2007;26(15):2202-11

26. Will K, Warnecke G, Wiesmüller $L$, Deppert W. Specific interaction of mutant p53 with regions of matrix attachment region DNA elements (MARs) with a high potential for base-unpairing. Proc Natl Acad Sci. 1998;95(23):13681-6.

27. Do PM, Varanasi L, Fan S, Li C, Kubacka I, Newman V, et al. Mutant p53 cooperates with ETS2 to promote etoposide resistance. Genes Dev. 2012;26(8):830-45.

28. Liu K, Ling S, Lin W-C. TopBP1 mediates mutant p53 gain of function through NF-Y and p63/p73. Mol Cell Biol. 2011;31(22):4464-81.

29. Valenti F, Fausti F, Biagioni F, Shay T, Fontemaggi G, Domany E, et al. Mutant p53 oncogenic functions are sustained by Plk2 kinase through an autoregulatory feedback loop. Cell Cycle. 2011;10(24):4330-40.

30. Di Agostino S, Strano S, Emiliozzi V, Zerbini V, Mottolese M, Sacchi A et al. Gain of function of mutant p53: the mutant p53/NF-Y protein complex reveals an aberrant transcriptional mechanism of cell cycle regulation. Cancer Cell. 2006;10(3):191-202.

31. Neilsen PM, Noll JE, Suetani RJ, Schulz RB, Al-Ejeh F, Evdokiou A, et al. Mutant p53 uses p63 as a molecular chaperone to alter gene expression and induce a pro-invasive secretome. Oncotarget. 2011;2(12):1203.

32. Schärer $\mathrm{E}$, Lggo R. Mammalian $\mathrm{p} 53$ can function as a transcription factor in yeast. Nucleic Acids Res. 1992;20(7):1539-45.

33. Strano S, Fontemaggi G, Costanzo A, Rizzo MG, Monti O, Baccarini A, et al. Physical interaction with human tumor-derived p53 mutants inhibits p63 activities. J Biol Chem. 2002;277(21):18817-26.

34. Girardini JE, Napoli M, Piazza S, Rustighi A, Marotta C, Radaelli E, et al. A Pin1/mutant p53 axis promotes aggressiveness in breast cancer. Cancer Cell. 2011;20(1):79-91.

35. Irwin M, Marin MC, Phillips AC, Seelan RS, Smith DI, Liu W, et al. Role for the p53 homologue p73 in E2F-1-induced apoptosis. Nature. 2000;407(6804):645-8.

36. Adorno M, Cordenonsi M, Montagner M, Dupont S, Wong C, Hann B, et al. A mutant-p53/Smad complex opposes p63 to empower TGF $\beta$ induced metastasis. Cell. 2009;137(1):87-98.

37. Noll J, Jeffery J, Al-Ejeh F, Kumar R, Khanna K, Callen D, et al. Mutant p53 drives multinucleation and invasion through a process that is suppressed by ANKRD11. Oncogene. 2012;31(23):2836-48.

38. Flores ER, Sengupta S, Miller JB, Newman JJ, Bronson R, Crowley D, et al. Tumor predisposition in mice mutant for p63 and p73: evidence for broader tumor suppressor functions for the p53 family. Cancer Cell. 2005;7(4):363-73.

39. Su X, Chakravarti D, Cho MS, Liu L, Gi YJ, Lin Y-L, et al. TAp63 suppresses metastasis through coordinate regulation of Dicer and miRNAs. Nature. 2010;467(7318):986-90.

40. Muller PA, Caswell PT, Doyle B, Iwanicki MP, Tan EH, Karim S, et al. Mutant p53 drives invasion by promoting integrin recycling. Cell. 2009:139(7):1327-41.
41. Muller P, Trinidad A, Timpson P, Morton J, Zanivan S, Van Den Berghe $P$, et al. Mutant p53 enhances MET trafficking and signalling to drive cell scattering and invasion. Oncogene. 2013;32(10):1252-65.

42. Rainero E, Caswell PT, Muller PA, Grindlay J, McCaffrey MW, Zhang Q, et al. Diacylglycerol kinase a controls RCP-dependent integrin trafficking to promote invasive migration. J Cell Biol. 2012;196(2):277-95.

43. Strano S, Blandino G. p73-mediated chemosensitivity: a preferential target of oncogenic mutant p53. Cell Cycle. 2003;2(4):345-6.

44. Neilsen PM, Noll JE, Mattiske S, Bracken CP, Gregory PA, Schulz RB, et al. Mutant p53 drives invasion in breast tumors through up-regulation of miR-155. Oncogene. 2013;32(24):2992-3000.

45. Tucci P, Agostini M, Grespi F, Markert EK, Terrinoni A, Vousden KH, et al. Loss of p63 and its microRNA-205 target results in enhanced cell migration and metastasis in prostate cancer. Proc Natl Acad Sci. 2012;109(38):15312-7.

46. Deng X, Li Y, Gu S, Chen Y, Yu B, Su J, et al. p53 affects PGC1 a stability through AKT/GSK-3 $\beta$ to enhance cisplatin sensitivity in non-small cell lung cancer. Front Oncol. 2020;10:1252.

47. Freed-Pastor WA, Mizuno H, Zhao X, Langerød A, Moon S-H, RodriguezBarrueco R, et al. Mutant p53 disrupts mammary tissue architecture via the mevalonate pathway. Cell. 2012;148(1-2):244-58.

48. Sigal A, Matas D, Almog N, Goldfinger N, Rotter V. The C-terminus of mutant p53 is necessary for its ability to interfere with growth arrest or apoptosis. Oncogene. 2001;20(35):4891-8.

49. Song $H$, Hollstein $M, X u Y$. p53 gain-of-function cancer mutants induce genetic instability by inactivating ATM. Nat Cell Biol. 2007;9(5):573-80.

50. Solomon H, Buganim Y, Kogan-Sakin I, Pomeraniec L, Assia Y, Madar S, et al. Various p53 mutant proteins differently regulate the Ras circuit to induce a cancer-related gene signature. J Cell Sci. 2012;125(13):3144-52.

51. Restle A, Färber M, Baumann C, Böhringer M, Scheidtmann KH, MüllerTidow $C$, et al. Dissecting the role of p53 phosphorylation in homologous recombination provides new clues for gain-of-function mutants. Nucleic Acids Res. 2008;36(16):5362.

52. Haupt Y, Maya R, Kazaz A, Oren M. Mdm2 promotes the rapid degradation of p53. Nature. 1997;387(6630):296-9.

53. Kubbutat $\mathrm{MH}$, Jones $\mathrm{SN}$, Vousden $\mathrm{KH}$. Regulation of p53 stability by Mdm2. Nature. 1997;387(6630):299-303.

54. Fukuda T, Kigoshi-Tansho Y, Naganuma T, Kazaana A, Okajima T, Tsuruta F, et al. CACUL1/CAC1 attenuates p53 activity through PML post-translational modification. Biochem Biophys Res Commun. 2017:482(4):863-9.

55. Meek DW, Anderson CW. Posttranslational modification of p53: cooperative integrators of function. Cold Spring Harb Perspect Biol. 2009. https://doi.org/10.1101/cshperspect.a000950.

56. Dai C, Gu W. p53 post-translational modification: deregulated in tumorigenesis. Trends Mol Med. 2010;16(11):528-36.

57. Loughery J, Cox M, Smith LM, Meek DW. Critical role for p53-serine 15 phosphorylation in stimulating transactivation at p53-responsive promoters. Nucleic Acids Res. 2014;42(12):7666-80.

58. Shieh S-Y, Ikeda M, Taya Y, Prives C. DNA damage-induced phosphorylation of p53 alleviates inhibition by MDM2. Cell. 1997;91(3):325-34.

59. Sakaguchi K, Herrera JE, Saito SI, Miki T, Bustin M, Vassilev A, et al. DNA damage activates p53 through a phosphorylation-acetylation cascade. Genes Dev. 1998;12(18):2831-41.

60. Dahl ES, Aird KM. Ataxia-telangiectasia mutated modulation of carbon metabolism in cancer. Front Oncol. 2017;7:291.

61. Chehab NH, Malikzay A, Stavridi ES, Halazonetis TD. Phosphorylation of Ser-20 mediates stabilization of human p53 in response to DNA damage. Proc Natl Acad Sci. 1999;96(24):13777-82.

62. Liebl MC, Hofmann TG. Cell fate regulation upon DNA damage: p53 serine 46 kinases pave the cell death road. BioEssays. 2019;41(12):1900127.

63. Yoshida S, Yoshida K. Multiple functions of DYRK2 in cancer and tissue development. FEBS Lett. 2019;593(21):2953-65.

64. Avantaggiati ML, Ogryzko V, Gardner K, Giordano A, Levine AS, Kelly K. Recruitment of p300/CBP in p53-dependent signal pathways. Cell. 1997;89(7):1175-84

65. Lill NL, Grossman SR, Ginsberg D, DeCaprio J, Livingston DM. Binding and modulation of p53 by p300/CBP coactivators. Nature. 1997;387(6635):823-7. 
66. Gillotin S, LuX. The ASPP proteins complex and cooperate with p300 to modulate the transcriptional activity of p53. FEBS Lett. 2011;585(12):1778-82.

67. Ghosh R, Kaypee S, Shasmal M, Kundu TK, Roy S, Sengupta J. Tumor Suppressor p53-mediated structural reorganization of the transcriptional coactivator p300. Biochemistry. 2019;58(32):3434-43.

68. Wang $Y$, Chen $Y$, Chen Q, Zhang X, Wang H, Wang Z, et al. The role of acetylation sites in the regulation of p53 activity. Mol Biol Rep. 2020;47(1):381-91.

69. Wang D, Kon N, Lasso G, Jiang L, Leng W, Zhu W-G, et al. Acetylationregulated interaction between $\mathrm{p} 53$ and SET reveals a widespread regulatory mode. Nature. 2016;538(7623):118-22.

70. Zhang J, Shen L, Sun L-Q. The regulation of radiosensitivity by $p 53$ and its acetylation. Cancer Lett. 2015;363(2):108-18.

71. Lee C-W, Sørensen TS, Shikama N, La Thangue NB. Functional interplay between p53 and E2F through co-activator p300. Oncogene. 1998;16(21):2695-710.

72. Grossman SR, Deato ME, Brignone C, Chan HM, Kung AL, Tagami H, et al. Polyubiquitination of p53 by a ubiquitin ligase activity of p300. Science. 2003:300(5617):342-4.

73. Abaev-Schneiderman E, Admoni-Elisha L, Levy D. SETD3 is a positive regulator of DNA-damage-induced apoptosis. Cell Death Dis. 2019;10(2):1-10

74. Raposo AE, Piller SC. Protein arginine methylation: an emerging regulator of the cell cycle. Cell Div. 2018;13(1):1-16.

75. Huang J, Sengupta R, Espejo AB, Lee MG, Dorsey JA, Richter M, et al. p53 is regulated by the lysine demethylase LSD1. Nature. 2007:449(7158):105-8.

76. Chuikov S, Kurash JK, Wilson JR, Xiao B, Justin N, Ivanov GS, et al. Regulation of p53 activity through lysine methylation. Nature. 2004:432(7015):353-60.

77. Jansson M, Durant ST, Cho E-C, Sheahan S, Edelmann M, Kessler B, et al. Arginine methylation regulates the p53 response. Nat Cell Biol. 2008;10(12):1431-9.

78. Li Y, Chitnis N, Nakagawa H, Kita Y, Natsugoe S, Yang Y, et al. PRMT5 is required for lymphomagenesis triggered by multiple oncogenic drivers. Cancer Discov. 2015;5(3):288-303.

79. Huang J, Perez-Burgos L, Placek BJ, Sengupta R, Richter M, Dorsey JA, et al. Repression of p53 activity by Smyd2-mediated methylation. Nature. 2006;444(7119):629-32.

80. Shi X, Kachirskaia I, Yamaguchi H, West LE, Wen H, Wang EW, et al. Modulation of p53 function by SET8-mediated methylation at lysine 382. Mol Cell. 2007;27(4):636-46.

81. Stommel JM, Marchenko ND, Jimenez GS, Moll UM, Hope TJ, Wahl GM. A leucine-rich nuclear export signal in the p53 tetramerization domain: regulation of subcellular localization and p53 activity by NES masking. EMBO J. 1999;18(6):1660-72.

82. Zhang Y, Xiong Y. A p53 amino-terminal nuclear export signal inhibited by DNA damage-induced phosphorylation. Science. 2001;292(5523):1910-5.

83. Chen L, Chen J. MDM2-ARF complex regulates p53 sumoylation. Oncogene. 2003;22(34):5348-57.

84. Garner E, Raj K. Protective mechanisms of p53-p21-pRb proteins against DNA damage-induced cell death. Cell Cycle. 2008;7(3):277-82.

85. Kung C-P, Khaku S, Jennis M, Zhou Y, Murphy ME. Identification of TRIML2, a novel p53 target, that enhances p53 SUMOylation and regulates the transactivation of proapoptotic genes. Mol Cancer Res. 2015:13(2):250-62.

86. Naidu SR, Lakhter AJ, Androphy EJ. PIASy-mediated Tip60 sumoylation regulates p53-induced autophagy. Cell Cycle. 2012;11(14):2717-28.

87. Mihara M, Erster S, Zaika A, Petrenko O, Chittenden T, Pancoska P, et al. p53 has a direct apoptogenic role at the mitochondria. Mol Cell. 2003;11(3):577-90.

88. Heo K-S, Berk BC, Abe J-I. Disturbed flow-induced endothelial proatherogenic signaling via regulating post-translational modifications and epigenetic events. Antioxid Redox Signal. 2016;25(7):435-50.

89. Ashikari D, Takayama K, Tanaka T, Suzuki Y, Obinata D, Fujimura T, et al. Androgen induces G3BP2 and SUMO-mediated p53 nuclear export in prostate cancer. Oncogene. 2017;36(45):6272-81.
90. Yau RG, Doerner K, Castellanos ER, Haakonsen DL, Werner A, Wang N, et al. Assembly and function of heterotypic ubiquitin chains in cellcycle and protein quality control. Cell. 2017;171(4):918-33.e20.

91. Bang S, Kaur S, Kurokawa M. Regulation of the p53 family proteins by the ubiquitin proteasomal pathway. Int J Mol Sci. 2020;21(1):261.

92. Chen L, Liu S, Tao Y. Regulating tumor suppressor genes: post-translational modifications. Signal Transduct Target Ther. 2020;5(1):1-25.

93. Niu G, Wright KL, Ma Y, Wright GM, Huang M, Irby R, et al. Role of Stat 3 in regulating p53 expression and function. Mol Cell Biol. 2005;25(17):7432-40.

94. Grivennikov SI, Greten FR, Karin M. Immunity, inflammation, and cancer. Cell. 2010;140(6):883-99.

95. Grivennikov SI, Karin M. Dangerous liaisons: STAT3 and NF-KB collaboration and crosstalk in cancer. Cytokine Growth Factor Rev. 2010;21(1):11-9.

96. Li N, Grivennikov SI, Karin M. The unholy trinity: inflammation, cytokines, and STAT3 shape the cancer microenvironment. Cancer Cell. 2011;19(4):429-31.

97. Yu H, Yue X, Zhao Y, Li X, Wu L, Zhang C, et al. LIF negatively regulates tumour-suppressor p53 through Stat3/ID1/MDM2 in colorectal cancers. Nat Commun. 2014;5(1):1-12.

98. Lin J, Jin X, Rothman K, Lin H-J, Tang H, Burke W. Modulation of signal transducer and activator of transcription 3 activities by p53 tumor suppressor in breast cancer cells. Can Res. 2002;62(2):376-80.

99. Lin J, Tang H, Jin X, Jia G, Hsieh J-T. p53 regulates Stat3 phosphorylation and DNA binding activity in human prostate cancer cells expressing constitutively active Stat3. Oncogene. 2002;21(19):3082-8.

100. Schulz-Heddergott R, Stark N, Edmunds SJ, Li J, Conradi L-C, Bohnenberger $\mathrm{H}$, et al. Therapeutic ablation of gain-of-function mutant p53 in colorectal cancer inhibits Stat3-mediated tumor growth and invasion. Cancer Cell. 2018:34(2):298-314.e7.

101. Klemke L, Fehlau CF, Winkler N, Toboll F, Singh SK, Moll UM, et al. The gain-of-function p53 R248W mutant promotes migration by STAT3 deregulation in human pancreatic cancer cells. Front Oncol. 2021:11:1622

102. Lapidot M, Case AE, Larios D, Gandler HI, Meng C, Tošić l, et al. Inhibitors of the transcription factor STAT3 decrease growth and induce immune response genes in models of malignant pleural mesothelioma (MPM). Cancers. 2021;13(1):7.

103. Webster GA, Perkins ND. Transcriptional cross talk between NF-kB and p53. Mol Cell Biol. 1999;19(5):3485-95.

104. Kawauchi K, Araki K, Tobiume K, Tanaka N. p53 regulates glucose metabolism through an IKK-NF-KB pathway and inhibits cell transformation. Nat Cell Biol. 2008;10(5):611-8.

105. Ryan KM, Ernst MK, Rice NR, Vousden KH. Role of NF-KB in p53-mediated programmed cell death. Nature. 2000;404(6780):892-7.

106. Chien $Y$, Scuoppo C, Wang $X$, Fang $X$, Balgley B, Bolden JE, et al. Control of the senescence-associated secretory phenotype by NF-KB promotes senescence and enhances chemosensitivity. Genes Dev. 2011;25(20):2125-36.

107. Lowe JM, Menendez D, Bushel PR, Shatz M, Kirk EL, Troester MA, et al. p53 and NF-KB coregulate proinflammatory gene responses in human macrophages. Can Res. 2014;74(8):2182-92.

108. Cooks T, Pateras IS, Tarcic O, Solomon H, Schetter AJ, Wilder S, et al. Mutant p53 prolongs NF-KB activation and promotes chronic inflammation and inflammation-associated colorectal cancer. Cancer Cell. 2013:23(5):634-46.

109. Gurova KV, Hill JE, Guo C, Prokvolit A, Burdelya LG, Samoylova E, et al. Small molecules that reactivate p53 in renal cell carcinoma reveal a NF-kB-dependent mechanism of p53 suppression in tumors. Proc Natl Acad Sci. 2005;102(48):17448-53.

110. Gasparian AV, Burkhart CA, Purmal AA, Brodsky L, Pal M, Saranadasa M, et al. Curaxins: anticancer compounds that simultaneously suppress NF-kB and activate p53 by targeting FACT. Sci Transl Med. 2011. https:// doi.org/10.1126/scitranslmed.3002530.

111. Binayke A, Mishra S, Suman P, Das S, Chander H. Awakening the "guardian of genome": reactivation of mutant p53. Cancer Chemother Pharmacol. 2019:83(1):1-15.

112. Liu T, Zhou L, Li D, Andl T, Zhang Y. Cancer-associated fibroblasts build and secure the tumor microenvironment. Front Cell Dev Biol. 2019;7:60 
113. Chiantore MV, Vannucchi $S$, Accardi $R$, Tommasino M, Percario ZA, Vaccari $G$, et al. Interferon- $\beta$ induces cellular senescence in cutaneous human papilloma virus-transformed human keratinocytes by affecting p53 transactivating activity. PLoS ONE. 2012;7(5):e36909.

114. Takaoka A, Hayakawa S, Yanai H, Stoiber D, Negishi H, Kikuchi H, et al. Integration of interferon- $\alpha / \beta$ signalling to $p 53$ responses in tumour suppression and antiviral defence. Nature. 2003;424(6948):516-23.

115. Lujambio A, Akkari L, Simon J, Grace D, Tschaharganeh DF, Bolden JE, et al. Non-cell-autonomous tumor suppression by p53. Cell. 2013;153(2):449-60

116. Madar S, Harel E, Goldstein I, Stein Y, Kogan-Sakin I, Kamer I, et al. Mutant p53 attenuates the anti-tumorigenic activity of fibroblastssecreted interferon beta. PLoS ONE. 2013;8(4):e61353.

117. Li L-N, Wang D-R, Sato M, Kojima N, Imai K, Higashi N, et al. Extracellular matrix-regulated p53 expression and nuclear localization in cultured Detroit 562 cells derived from pharyngeal carcinoma. Arch Histol Cytol. 2003;66(5):419-28.

118. Petrova V, Annicchiarico-Petruzzelli M, Melino G, Amelio I. The hypoxic tumour microenvironment. Oncogenesis. 2018;7(1):1-13.

119. Yoshida D, Kim K, Noha M, Teramoto A. Hypoxia inducible factor 1-a regulates of platelet derived growth factor-B in human glioblastoma cells. J Neurooncol. 2006;76(1):13-21.

120. Amelio I, Mancini M, Petrova V, Cairns RA, Vikhreva P, Nicolai S, et al. p53 mutants cooperate with HIF-1 in transcriptional regulation of extracellular matrix components to promote tumor progression. Proc Natl Acad Sci. 2018;115(46):E10869-78.

121. Cui Y, Guo G. Immunomodulatory function of the tumor suppressor p53 in host immune response and the tumor microenvironment. Int J Mol Sci. 2016;17(11):1942

122. Wang B, Niu D, Lai L, Ren EC. p53 increases MHC class I expression by upregulating the endoplasmic reticulum aminopeptidase ERAP1. Nat Commun. 2013;4(1):1-11.

123. Allavena $\mathrm{P}$, Mantovani A. Immunology in the clinic review series; focus on cancer: tumour-associated macrophages: undisputed stars of the inflammatory tumour microenvironment. Clin Exp Immunol. 2012;167(2):195-205.

124. Quigley D, Silwal-Pandit L, Dannenfelser R, Langerød A, Vollan HKM, Vaske C, et al. Lymphocyte invasion in IC10/basal-like breast tumors is associated with wild-type TP53. Mol Cancer Res. 2015;13(3):493-501.

125. Wellenstein MD, Coffelt SB, Duits DE, van Miltenburg MH, Slagter M, de Rink I, et al. Loss of p53 triggers WNT-dependent systemic inflammation to drive breast cancer metastasis. Nature. 2019;572(7770):538-42.

126. Thiem A, Hesbacher S, Kneitz H, di Primio T, Heppt MV, Hermanns HM, et al. IFN-gamma-induced PD-L1 expression in melanoma depends on p53 expression. J Exp Clin Cancer Res. 2019;38(1):1-15.

127. Alsaab HO, Sau S, Alzhrani R, Tatiparti K, Bhise K, Kashaw SK, et al. PD-1 and PD-L1 checkpoint signaling inhibition for cancer immunotherapy: mechanism, combinations, and clinical outcome. Front Pharmacol. 2017:8:561.

128. Liu Z, Jiang Z, Gao Y, Wang L, Chen C, Wang X. TP53 mutations promote immunogenic activity in breast cancer. J Oncol. 2019. https://doi.org/ $10.1155 / 2019 / 5952836$.

129. Shatz M, Shats I, Menendez D, Resnick MA. p53 amplifies Toll-like receptor 5 response in human primary and cancer cells through interaction with multiple signal transduction pathways. Oncotarget. 2015;6(19):16963.

130. Tomso DJ, Inga A, Menendez D, Pittman GS, Campbell MR, Storici $\mathrm{F}$, et al. Functionally distinct polymorphic sequences in the human genome that are targets for p53 transactivation. Proc Natl Acad Sci. 2005;102(18):6431-6.

131. Korneev KV, Atretkhany K-SN, Drutskaya MS, Grivennikov SI, Kuprash DV, Nedospasov SA. TLR-signaling and proinflammatory cytokines as drivers of tumorigenesis. Cytokine. 2017:89:127-35

132. He W, Liu Q, Wang L, Chen W, Li N, Cao X. TLR4 signaling promotes immune escape of human lung cancer cells by inducing immunosuppressive cytokines and apoptosis resistance. Mol Immunol. 2007;44(11):2850-9

133. Wang E, Qian Z-R, Nakasono M, Tanahashi T, Yoshimoto K, Bando Y, et al. High expression of Toll-like receptor 4/myeloid differentiation factor 88 signals correlates with poor prognosis in colorectal cancer. Br J Cancer. 2010;102(5):908-15.
134. Yang H, Wang B, Wang $T$, Xu L, He C, Wen H, et al. Toll-like receptor 4 prompts human breast cancer cells invasiveness via lipopolysaccharide stimulation and is overexpressed in patients with lymph node metastasis. PLoS ONE. 2014;9(10):e109980.

135. Agupitan AD, Neeson P, Williams S, Howitt J, Haupt S, Haupt Y. P53: a guardian of immunity becomes its saboteur through mutation. Int J Mol Sci. 2020;21(10):3452.

136. Pradere J-P, Dapito DH, Schwabe RF. The Yin and Yang of Toll-like receptors in cancer. Oncogene. 2014;33(27):3485-95.

137. Taura M, Fukuda R, Suico MA, Eguma A, Koga T, Shuto T, et al. TLR3 induction by anticancer drugs potentiates poly I: C-induced tumor cell apoptosis. Cancer Sci. 2010;101(7):1610-7.

138. Gonzalez $\mathrm{H}$, Hagerling C, Werb Z. Roles of the immune system in cancer: from tumor initiation to metastatic progression. Genes Dev. 2018;32(19-20):1267-84.

139. Zheng S-J, Lamhamedi-Cherradi S-E, Wang P, Xu L, Chen YH. Tumor suppressor p53 inhibits autoimmune inflammation and macrophage function. Diabetes. 2005;54(5):1423-8.

140. Mantovani F, Collavin L, Del Sal G. Mutant p53 as a guardian of the cancer cell. Cell Death Differ. 2019;26(2):199-212.

141. Neerincx M, Sie D, Van De Wiel M, Van Grieken N, Burggraaf J-D, Dekker $\mathrm{H}$, et al. MiR expression profiles of paired primary colorectal cancer and metastases by next-generation sequencing. Oncogenesis 2015:4(10):e170.

142. Cooks T, Pateras IS, Jenkins LM, Patel KM, Robles Al, Morris J, et al. Mutant p53 cancers reprogram macrophages to tumor supporting macrophages via exosomal miR-1246. Nat Commun. 2018;9(1):1-15.

143. Beck J, Turnquist C, Horikawa I, Harris C. Targeting cellular senescence in cancer and aging: Roles of p53 and its isoforms. Carcinogenesis. 2020;41(8):1017-29.

144. Boros J, Donaldson IJ, O'Donnell A, Odrowaz ZA, Zeef L, Lupien M, et al. Elucidation of the ELK1 target gene network reveals a role in the coordinate regulation of core components of the gene regulation machinery. Genome Res. 2009;19(11):1963-73.

145. Alessio N, Capasso S, Ferone A, Di Bernardo G, Cipollaro M, Casale F, et al. Misidentified human gene functions with mouse models: the case of the retinoblastoma gene family in senescence. Neoplasia. 2017;19(10):781-90.

146. Alessio N, Squillaro T, Di Bernardo G, Galano G, De Rosa R, Melone MA, et al. Increase of circulating IGFBP-4 following genotoxic stress and its implication for senescence. Elife. 2020;9:e54523.

147. Lujambio A. To clear, or not to clear (senescent cells)? That is the question Bioessays. 2016;38:S56-64.

148. Talens F, Van Vugt MA. Inflammatory signaling in genomically instable cancers. Cell Cycle. 2019;18(16):1830-48.

149. Hu W, Feng Z, Levine AJ. The regulation of multiple p53 stress responses is mediated through MDM2. Genes Cancer. 2012;3(3-4):199-208.

150. Mijit M, Caracciolo V, Melillo A, Amicarelli F, Giordano A. Role of p53 in the Regulation of Cellular Senescence. Biomolecules. 2020;10(3):420.

151. Valente JF, Queiroz JA, Sousa F. p53 as the focus of gene therapy: past, present and future. Curr Drug Targets. 2018:19(15):1801-17.

152. Joerger AC, Fersht AR. Structural biology of the tumor suppressor p53 and cancer-associated mutants. Adv Cancer Res. 2007:97:1-23.

153. Bossi G, Marampon F, Maor-Aloni R, Zani B, Rotter V, Oren M, et al. Conditional RNA interference in vivo to study mutant p53 oncogenic gain of function on tumor malignancy. Cell Cycle. 2008;7(12):1870-9.

154. Loh SN. The missing zinc: p53 misfolding and cancer. Metallomics. 2010;2(7):442-9.

155. Butler JS, Loh SN. Structure, function, and aggregation of the zinc-free form of the p53 DNA binding domain. Biochemistry. 2003;42(8):2396-403.

156. Pintus S, Ivanisenko N, Demenkov P, Ivanisenko T, Ramachandran S, Kolchanov N, et al. The substitutions G245C and G245D in the Zn2+binding pocket of the p53 protein result in differences of conformational flexibility of the DNA-binding domain. J Biomol Struct Dyn. 2013:31(1):78-86

157. Puca R, Nardinocchi L, Porru M, Simon AJ, Rechavi G, Leonetti C, et al. Restoring p53 active conformation by zinc increases the response of mutant p53 tumor cells to anticancer drugs. Cell Cycle. 2011;10(10):1679-89. 
158. Yu X, Vazquez A, Levine AJ, Carpizo DR. Allele-specific p53 mutant reactivation. Cancer Cell. 2012;21(5):614-25.

159. Duffy MJ, Synnott NC, Crown J. Mutant p53 in breast cancer: potential as a therapeutic target and biomarker. Breast Cancer Res Treat. 2018;170(2):213-9.

160. Duffy MJ, Synnott NC, Crown J. Mutant p53 as a target for cancer treatment. Eur J Cancer. 2017:83:258-65.

161. Zhang W-W, Li L, Li D, Liu J, Li X, Li W, et al. The first approved gene therapy product for cancer Ad-p53 (Gendicine): 12 years in the clinic. Hum Gene Ther. 2018;29(2):160-79.

\section{Publisher's Note}

Springer Nature remains neutral with regard to jurisdictional claims in published maps and institutional affiliations.

- fast, convenient online submission

- thorough peer review by experienced researchers in your field

- rapid publication on acceptance

- support for research data, including large and complex data types

- gold Open Access which fosters wider collaboration and increased citations

- maximum visibility for your research: over $100 \mathrm{M}$ website views per year

At $\mathrm{BMC}$, research is always in progress.

Learn more biomedcentral.com/submissions 